\title{
Acontecimento, memória e televisão
}

Suzana Kilpp

\begin{abstract}
Resumo
Os panoramas televisivos são duraçōes audiovisuais engendradas tecnicamente que têm ainda hoje grande opacidade. Neles, produzem-se, entre outros, os efeitos de realidade, de tempo real e de horizonte, que são fascinantes caracteristicas dos mundos televisivos. O debate sobre acontecimento, memória e história passa hoje necessariamente por uma discussão sobre a televisão e sobre os mundos que instaura em seus panoramas.
\end{abstract}

Palavras-chave: mundos televisivos; memória; acontecimento televisivo.

\begin{abstract}
The televising landscapes are andiovisuals durations technical engendered. They still have today a great opacity. In them, are produced. among others. the effects of reality, real time and horizon, fascinating characteristics of the televising worlds. The debate about event, memory and history pass today necessarily for a discussion about television and about the worlds that establishes in its landscapes.
\end{abstract}

Key words: televising worlds; memon; televising event.

\footnotetext{
- XI POSCOM. Artigo apresentado na Mesa: Comunicação, Acontecimento e Memória. Decorre da pesquisa O Voyeurismo Televisivo (2003-2005), realizada com apoio da FAPERGS.

- Doutora em Comunicação, professora e pesquisadora do PPG em Comuniçação e do curso de Comunicação Digital da UNISINOS, onde também coordena o GP em Audiovisualidades.
} 


\section{Tevê: imagens, memória e percepção}

Os panoramas televisivos são durações com extensividade nos quais se dão a ver um compósito de quadros de experiência e significação que é próprio da tevê. Nossa atenção, porém, dirige-se em geral para as imagens audiovisuais sintéticas que neles aparecem molduradas, seja porque são as que têm mais forte apelo tátil seja porque a tevê tende a ocultar ou enevoar nos panoramas os modos como essas imagens são produzidas. Esse forte teor conteudístico das imagens audiovisuais de programas e anúncios publicitários e a aparência replicante das formas (estéticas, mas também éticas) dificultam que percebamos as imagens analíticas presentes nos panoramas.

A maior ou menor centralidade que a espectação de TV tem em nossas vidas age sobre as expectativas que temos em relação aos panoramas - quase sempre entendendo que é nos conteúdos percebidos nas imagens síntese que tais expectativas são satisfeitas ou frustradas. E, até porque a TV se enuncia como sendo capaz disso, muitas vezes esperamos dela coisas que não são de sua alçada ou que não estão ao seu alcance.

Refiro-me aqui àquela falta de memória da origem, que nos move milenarmente e que nos tem feito criar incessantemente os dispositivos com os quais fantasiamos poder chegar ao eso ha sido. Prestou-se para isso a arte, noutros tempos. Mas foram as tecnologias do olhar, principalmente as câmeras, as em que mais depositamos nossas esperanças. Primeiro a

142 fotografia, depoị o cinema; agora é a vez da TV se prestar a que cobremos dela a produção e veiculação de imagens espectrais...

Se aceitarmos que ela não é capaz disso, qual seria então a natureza das imagens televisivas? Não são também, em geral, da ordem dos mundos virtuais, como são entendidas aquelas que estão mais relacionadas com a cibercultura... Como entendê-las, então, em sua conexão com o eso ha sido, com a memória e o acontecimento?

Tenho insistido na necessidade de se adentrar a telinha, aprender as gramáticas televisivas, analisar os mundos televisivos e chegar ao que a tevê enuncia não diretamente sobre o que parece ser o teor das imagens que veicula (justamente o eso ha sido), mas sobre ela mesma. Ainda mais que, nesse momento, a TV rodopia sobre seu próprio umbigo e, como Narciso, apaixonada por sua imagem, reflete-a especularmente a todo instante... Não são apenas os atravessamentos dos promos dos programas na programação em fluxo, ou a entrada de protagonistas de um programa em outro, ou as atualidades da programação de TV pautando telejornais, e assim por diante. É também o atravessamento pesado, em vários sentidos, de uma enunciação da TV reality, que é feita principalmente nos vários reality shows em cartaz.

Mas que importância pode ter a veiculação dela mesma para nós outros? É que, ao assumir sua própria programação e seus negócios como teor, a TV dá a ver a natureza de suas imagens. Por conta de uma disputa 
interna por certas vinculações e veiculações ${ }^{\prime}$, os panoramas são iluminados por imagens mais tensas, que é um cenário propício à percepção de certos protagonismos no eso ha sido, sendo que eles são ali enunciados enquanto ao mesmo tempo se instauram os mundos televisivos.

Porém, adentrar a telinha implica perceber para além das imagens síntese e operar num nível de percepção para além da memória hábito... Ora, a lécnica da televisão está num estágio ao qual corresponde um estágio do conhecimento da técnica, e tal conhecimento implica certas relações entre memória e percepção. Gostaria de assinalar algumas, a partir do que propôs Henri Bergson quase um século atrás.

O autor chama de matéria ao conjunto das imagens, sendo que imagem é uma existência situada entre a coisa e a representação. Já as percepções da matéria seriam 'essas mesmas imagens relacionadas à ação de uma certa imagem determinada, meu corpo' (Bergson, 1999:17). Inicialmente haveria o conjunto das imagens, e, nele, existiriam centros de ação contra os quais as imagens interessantes pareceriam se refletir. As percepções adviriam da reflexão dessas imagens, que são interessantes porque necessárias à ação presente. Portanto, o corpo é o que se desenharia no centro dessas percepções, e cada um percebe certos aspectos da matéria; ou, como prefiro dizer, são os nossos corpos que molduram nossa experiência da matéria.

Haveria na matéria algo além, mas não algo diferente daquilo que é percebido e a percepção não seria o objeto mais algo, mas o objeto menos algo: menos tudo o que não nos interessa. Segundo Bergson, o movimento de percepção ou de reconhecimento de uma imagem se faz a partir das imagens-lembrança de nossa memória, sendo que algumas lembranças seriam sempre dominantes, verdadeiros pontos brilhantes em torno dos quais os outros formam uma vaga nebulosidade. Esses pontos brilhantes multiplicamse à medida que se dilata nossa memória.

Em resumo, não haveria percepção que não estivesse impregnada de lembranças, de diferentes ordens e naturezas. Existiriam diferentes tons de vida mental, e nossa vida psicológica poderia se manifestar em alturas diferentes - ora mais perto, ora mais distante da ação, conforme o grau de nossa atenção à vida. 'Ao lado da consciência e da ciência, existe a vida', diz o autor. 'Existem tendências cujo estado se negligenciou e que se explicam simplesmente pela necessidade que temos de viver. ou seja, em realidade. de agir' (Bergson, 1999:232).

Creio que duas ou três gerações de TV - uma televisão que talvez tenha amadurecido. no Brasil, há uma geração, apenas - estão finalmente consolidando o conjunto de imagens no qual é possível re-conhecer imagens que interessam. e que interessam como outros corpos, como alteridade, dos quais devemos 
nos aproximar ou fugir... Creio, ainda, que já se produziram repertórios de imagens-lembrança, pessoais e coletivos, isto é, memórias, que permitem perceber inclusive o que chamo de o televisivo ou a tevê como o próprio da TV - sua imagicidade ${ }^{2}$.

Pretendo esclarecer adiante que esse televisivo tem as molduras sobrepostas como característica fundante, ainda que não exclusiva. Somos capazes hoje de percebê-las graças às imagens-lembrança ou, como prefiro, graças ao repertório de molduras e moldurações televisivas que já arquivamos em nossa memória.

\section{Televisão e memória}

Conhecer os modos como a televisão produz memória e os modos mais ou menos discretos que ela usa para sabotar memória é uma questão estratégica para a pesquisa, e em grande parte passa pelo reconhecimento do televisivo. Mas passa também por outras questões que é preciso referir antes.

Primeiro. A proposição de que o presente, relacionado às atualidades, é uma invenção dos jornalistas, assim como o passado, relacionado à memória, é uma invenção dos historiadores ${ }^{3}$ ainda causa certo constrangimento entre jornalistas. Entre historiadores já se naturalizou a percepção da história escrita como versão do acontecido, não apenas pela seleção de fontes e sua crítica

144 interna, como também pelo inevitável olhar do pesquisador. Por que seria diferente em relação ao jornal impresso, por exemplo? E, no entanto, também os historiadores raramente fazem uma crítica adequada do jornal de ontem quando o usam como fonte...

Anos atrás, o que eu estava propondo era uma aproximação entre os dois campos. Agora, mais uma vez estou trazendo ao debate algumas aproximações entre história, jornalismo e televisão, mas espero demonstrar que se trata de coisa diversa. De lá até aqui parece que perdeu força o emolduramento ${ }^{4}$ que insiste numa certa objetividade do discurso jornalístico; entretanto, é preciso retomar criticamente certas relações emblemáticas entre televisão e história, especialmente pelo modo que ocorrem no Brasil, como veremos em seguida.

Segundo. Muitas vezes se disse que o poder público, no Brasil, é negligente e omisso em relação ao patrimônio histórico ${ }^{5}$, e que o brasileiro é um povo sem memória. Sem entrar no mérito das assertivas, ou vincular uma à outra, cito-as para demarcar um importante território simbólico, também de grande opacidade. Para muitos brasileiros, a televisão aparece assim como baluarte da memória nacional, nos termos em que ela mesma enuncia para um conjunto de imagens, as quais podemos localizar nos jornais, nos documentários, nas novelas, nas séries, nos shows de artistas brasileiros, nos programas de entrevista com personalidades brasileiras, nos programas de auditório, etc. 
Operando sobre esse vazio (essa suposta falta de memória), suprindoo minimamente - ainda que não satisfatoriamente, até se admite - e produzindo sem cessar imagens sobre as atualidades, a televisão cria uma série de produtos, perfectíveis graças ao videoteipe, relacionados às atualidades de ontem. Sintoma de um gosto muito oportuno - oportunista, às vezes - pelo remake $\mathrm{e}$ pelo making of, tais imagens, inseridas na programação de tempos em tempos. mereceriam per se uma análise como lócus de (re) significação de personagens. fatos e acontecimentos. Advêm de arquivos privados das emissoras, nos quais se guarda especialmente a memória da TV brasileira, mas também boa parte da memória nacional.

Ainda antes do videoteipe, porém, a TV já fundou um emblemático discurso televisivo sobre memória e identidade nacional, a que chamo de brasilidade televisiva. Sem ir muito longe, recordemos apenas o ambiente tele-político de meados dos anos setenta. Na programação em fluxo nos habituamos então a assistir ao Jomal Nacional. às telenovelas brasileiras e às séries brasileiras, entre outros importantes programas de grande audiência; e a várias campanhas publicitárias, principalmente do Governo Federal, que operavam com imagens ou imaginários de brasilidade, inclusive coercitivamente em slogans como 'Brasil. Ame-o ou deixe-o'. Foi, possivelmente, o discurso mais articulado e de maior penetração dos que já se fez sobre a identidade nacional até hoje.

A partir daí se consolidou, em linguagem de tevê, uma programação brasileira ou abrasileirada, em grande parte dita 'em tempo real' e para todo os espectadores brasileiros residentes no país - que era até então. lembro, muito mais um conglomerado de regiões, muito diversas e desiguais entre si. Como todos os discursos fundadores, esse que enunciou a brasilidade televisiva dos anos setenta perdura como versão. E alimenta-se de certas memórias, que voltam em forma de remakes, reprises e em flashes que são inseridos eventualmente, mas com certa regularidade, na programação.

Terceiro. Não fossem esses motivos suficientes para que se considere a possibilidade de estarem se estabelecendo, no imaginário, associações mais ou menos fortes entre memória e televisão, há outro que interessa sobremaneira à pesquisa. As emissoras, ainda que se enunciem em outros termos, são cessionárias de canais públicos, mas mantêm sob sua exclusiva tutela todas as imagens de TV, sendo que a maioria dessas imagens memoriais já foi publicizada. O que explica ou justifica essa tutela? Com que legitimidade perdura tal situação? Como fica nosso direito de mirada?

O poder público brasileiro tem se omitido completamente. Penso que, ao contrário, e até a exemplo de outros países, deveríamos ter livre acesso a todas e quaisquer imagens produzidas e veiculadas pelas emissoras em qualquer tempo. Deveríamos poder dispor delas para nossas pesquisas do mesmo modo que dispomos de todos os textos publicados e. muito mais que 
acessar arquivos disponibilizados pelas emissoras em remakes, todos nós deveríamos poder desconstruir panoramas televisivos, desmontar as molduras e analisar os quadros de experiência e significação. Como diz enfaticamente Jacques Derrida:

La expresión 'derecho de mirada' (...) puede significar la autoridad abusiva, la autoridad usurpada, violentamente apropiada o impuesta allí donde no tenemos 'naturalmente' derecho. (...) ¿Quién tiene derecho de mirada sobre quién? El derecho, todo derecho, es en cierta forma derecho de mirada; todo derecho da derecho a la mirada. (Derrida, 1998:48)

El hecho de tener acceso a esos archivos, poder analizar su contenido, las modalidades de selección, interpretación, manipulación que presidieron su producción y circulación, todo eso es por lo tanto un derecho del ciudadano. (Derrida, 1998:51)

Parece-me fundamental rever tal contexto para que tenhamos, no Brasil, relações mais amigáveis entre os que fazem televisão e os que a pesquisam ou assistem, e para que possamos todos nos apropriar mais rapidamente do televisivo e das éticas originais que a TV instaura tecnicamente - e que sequer são entendidas, muitas vezes, por quem faz televisão, atrevo-me a dizer. Não se trata, portanto, de censura ou de qualquer interferência na programação 146 das emissoras, a princípio.

A princípio, penso como Wolton: ainda que a televisão ambicione ter um poder absoluto sobre nossa vida, ela não o tem, pois rapidamente compreendemos que ela não pode tudo. Mas ela tem muitos méritos, alguns que até achamos serem defeitos. Entre os méritos não reconhecidos da TV está o fato de ela ser 'um espetáculo de um gênero particular, destinado a um público imenso, anônimo e heterogêneo, inseparável de uma programação que garante uma oferta quase contínua de imagens de gêneros e status diferentes' (Wolton, 1996:67). O autor está fazendo aí a defesa da TV generalista em relação à segmentada, pois, segundo ele, 'ela não nos obriga a nos interessarmos por aquilo que interessa aos outros, mas, no mínimo, a reconhecermos a sua legitimidade' (Wolton, 1996:19).

Uma política da memória da TV no Brasil implicaria também, portanto, se houvesse, a preservação desses repertórios, heterogêneos e desiguais, de imagens veiculadas pelas emissoras, e a pesquisa de TV deveria levar sua dispersão mais em conta. Afinal, a televisão não é apenas uma ethicidade ${ }^{6}$ contraditória: ela é um ser plural, e é da sua natureza mesmo atualizar-se numa multiplicidade de tevês.

Diz-se que 'povo sem memória é povo sem passado e sem futuro'. E assim, por estar condenado a um continuum ou a uma sucessão de meras 
repetições, poderíamos concluir drasticamente ser esse um povo ou cultura sem história e sem vida! Essa é uma visão de história, a nossa, das sociedades modernas, no Ocidente, e é a ela que se relaciona o que estarei definindo como acontecimento.

Desde tal visão, e pelo disposto antes sobre memória e percepção, não é tão simples evocar o passado, porquanto a memória hábito nos leva naturalmente à percepção daquilo que interessa à ação presente. Naturalmente, a necessidade nos leva a estar no presente, e num presente que recomeça a todo instante; para evocar o passado, ao contrário, é preciso resistir à necessidade, ser capaz de fixar o devir por algum tempo. Como diz Bergson. se há ações livres ou pelo menos parcialmente indeterminadas, elas só podem pertencer a seres capazes de fixar, em intervalos regulares de tempo, o devir sobre o qual seu próprio devir se aplica, capazes de solidificá-lo em momentos distintos, de condensar deste modo sua matéria e, assimilando-a, digeri-la em movimentos de reação que passarão através das malhas da necessidade natural. (Bergson, 1999:247).

O modo de a memória operar sobre a percepção, e vice-versa, é o mesmo na percepção desinteressada de qualquer imagem quando se trata daquelas ações mais indeterminadas que relacionamos à produção de conhecimento e à criação artística. Na espectação de TV, por exemplo, as molduras e as moldurações que criam quadros de experiência e significação dos mundos televisivos não interessam à necessidade natural que temos de agir, e em geral não as percebemos. Interessam à pesquisa, porém, e aos homens de TV mais criativos.

Seguindo Bergson, então, mas também seguindo Benjamin (1986), Canevacci (1997) e Rolnik (1989), tenho estado a cartografar a meu modo essas molduras e moldurações a partir de imagens dialéticas. Como imagens criadas, seriam aquelas que tensionam as práticas homológicas e que fazem avançar as técnicas ou o estado da arte... Para fins de análise interessam particularmente porque, por conterem o velho e o novo, iluminam toda a constelação.

Em relação à história, as imagens dialéticas relacionam-se a uma certa descontinuidade, e quanto mais tensas são, mais ameaçam o continuum como rupturas possíveis. Derrotadas historicamente, adquirem uma certa opacidade no continuum, mas continuam a existir em estado latente, como potência.

Ao olhar para o passado, a prática habituada das emissoras é reeditar imagens, que são em geral de seu próprio arquivo - um recorte de outro recorte, portanto -, sendo que as reedições tendem a uma atualização do emolduramento original e a um tratamento técnico das imagens. Em geral são desprezadas as imagens que não interessam à ação presente da emissora, e entre elas estão as potências a que me refiro. Não é um olhar desinteressado, portanto, que move a TV na evocação do passado. 
Mas também não se trata de manipulações mal intencionadas como mùitas vezes se diz - embora até às vezes sejam -, mas do modo mesmo como acessamos a memória pela necessidade que temos de agir no presente. Esses remakes, que são enunciados como memória evocada, são na verdade imagens de outro grau, com outras molduras e outros sentidos e não podem ser confundidos com a pesquisa histórica digna desse nome. Acho inclusive que uma pesquisa que mostrasse o percurso de algumas dessas 'imagenslembrança' e as relacionasse com as 'imagens-lembrança' do passado inventado pelos historiadores seria extremamente interessante.

A memória à qual me referi anteriormente, não é a mesma coisa, portanto, que a memória televisiva que estou citando aqui, mas uma tem ingerência sobre a outra. Nos termos de Derrida, essa ethicidade é mais um artefato $^{7}$, como as atualidades que lhe deram origem, e, como veremos adiante, relaciona-se estreitamente com o acontecimento na produção do efeito de horizonte. Cem Anos de Cinema, Túnel do Tempo, Arquivo N, Vale a Pena Ver de Novo e outros tantos nomes são usados para designar programas relacionados a essa ethicidade. São programas nos quais a TV enuncia seu protagonismo na história.

No Brasil, a TV Globo e a Globo News são quem mais os produz, e não há de ser só porque provavelmente tenham mais imagens em arquivo do que as demais emissoras... A mostragem da participação da TV na invenção das atualidades e do passado, a ostentação do controle que detém sobre suas 148 imagens memoriais e a perfectibilização das imagens que exibe asseguram, enunciativamente, seu protagonismo também no futuro. Essa enunciação é replicante e faz parte de seu próprio continuum.

Já a memória televisiva da televisão é memória nos mundos televisivos, que foram instituídos no Brasil justamente nos anos setenta, na esteira do estado nascente dos sessenta. Esses mundos compartilham com outros mundos um certo imaginário de memória. Nos mundos televisivos é possível perceber claramente como é efetuado o movimento de atualização das imagenslembrança por determinado corpo.

Toda memória é atualizada, ainda que, talvez, não do modo escancarado que a TV pratica fazê-lo. Mas justamente por isso, e aí está outra vez um mérito seu, nas imagens analíticas da tevê se desvelam técnicas e éticas que têm a ver também com as sociedades e com o patrimônio histórico, por exemplo. Ora; convenhamos; todas as instituições se protegem do direito de mirada dos cidadãos. Todas produzem imagens (ou documentos e arquivos) memoriais que ficam mais ou menos fora do alcance dos cidadãos. $E$ todas inventam uma memória, a partir de seu próprio corpo, que perdura sempre como versão! 


\section{Televisão e acontecimento: apontamentos para uma}

futura pesquisa

Primeiro: a diferença do acontecimento. Derrida diz que o pensamento da diferença é um pensamento sobre um outro, e que o acontecimento. em sua singularidade, é o imprevisível do qual não é possível apropriar-se exatamente porque é outro. Ele é o que vem, e que não se espera que venha. Se houvesse previsão, programação, nĩo haveria nem acontecimento nem história. O acontecimento é uma diferença, uma descontinuidade. um recém chegado singular, porquanto esse 'recién llegado debe ser absolutamente otro, otro que espero no esperar, que no espero, cuya espera está hecha de una no espera, una espera sin lo que en filosofía se llama horizonte de expectativa' (Derrida, 1998:27). Mas também a chegada de algo ou de alguém que se espera pode ser surpreendente, como uma oportunidade inaudita, a cada vez que vem, de suceder algo totalmente novo; assim como pode surpreender que não venha aquilo ou aquele que se espera...

Entretanto, e por isso,

La llegada del acontecimiento es lo que no puede ni debe impedirse nunca, otro nombre del futuro mismo. No es que sea bueno, bueno en sí, que suceda todo o cualquier cosa; no es que haya que renunciar a impedir que ciertas cosas se produzcan (no habría entonces ninguna decisión, ninguna responsabilidad, ética, política u otra), pero uno no se opone jamás sino a acontecimientos de los que se piensa que obstruyen el porvenir o traen la muerte consigo, acontecimientos que ponen fin a la posibilidad del acontecimiento, a la apertura afirmativa para la venida del otro. (Derrida, 1998:24)

Segundo: a irredutibilidade do acontecimento no acontecimento televisivo ${ }^{9}$. Quando o autor analisa as relações entre acontecimento e televisão, ele alerta para que não se ceda à tentação de neutralizar tudo naquilo que se poderia chamar de embuste do embuste, a negação do acontecimento, pois, no interior do processo contraditório e heterogêneo da comunicação, a singularidade do acontecimento é sempre irredutivel.

Mas ele também adverte que não confundamos constantemente o presente com as atualidades, e que aprendamos a resistir à aparência das atualidades naTV:

Por más singular, irreductible, testaruda. dolorosa o trágica que sea la 'realidad' a la cual se refiere la 'actualidad'. esta nos llega a través de una hechura ficcional. No es posible analizarla más que al precio de un trabajo de resistencia, de contrainterpretación vigilante. etc. (Derrida. 1998:15) 
De fato, a televisão instaura mundos televisivos e moldura os gêneros de tal forma que, ao final, dá origem ao gênero televisivo. $O$ conceito se refere à realidade televisiva, que designei antes de TV reality - novamente uma ethicidade -, que pode ser mais ou menos documental ou ficcional. Ou seja, percebo no acontecimento televisivo, por mais documental que seja, um mínimo de ficcionalização; do mesmo modo, por mais ficcionalizado que possa ser, há nele sempre um mínimo do acontecimento, aquilo que é só dele e que não pode ser de outra coisa. A diferença entre a coisa (o acontecimento) e a coisa percebida, no caso percebida pela TV, é uma diferença de grau e não de natureza.

Terceiro: o acontecimento televisivo e o efeito de horizonte. Derrida diz que $o$ acontecimento televisivo produz um efeito de horizonte (horizonte de expectativa). Esse artefato fecharia as portas para o futuro, dando a impressão de que ele já chegou. É um paradoxo, pois pode acontecer qualquer coisa, diz ele, mas já aconteceu, e como tal é que teríamos, no acontecimento televisivo (ou nos sentidos para ele enunciados nas molduras de que falo) uma experiência de morte (da expectativa). O efeito de horizonte seria, de fato, uma impressão de não futuro, pois o futuro nem sequer pode acontecer $\mathrm{e}$ tudo já é passado, sendo que, a meu ver, a memória televisiva participa da criação desse efeito de horizonte, só que no sentido contrário da linha do horizonte...

Como se verá a seguir, não é uma visão apocalíptica da TV, mas outra 150 coisa. Diz o autor:

Esta doble experiencia que corresponde a la estructura del horizonte, también a la del duelo, no es nueva, desde luego. No hubo que esperar para ello las maquinas de las que hablamos, pero éstas le dieron una expansión tanto más poderosa que todavía estamos estupefactos. Lo estamos a partir de unas estructuras relativamente estables que hacen que, en términos generales, estemos construidos como los griegos, los fenicios o los hombres de la Edad Media, tengamos la misma estructura existencial o psicosociologica, y sin embargo ya no somos hombres de la Edad Media; resulta entonces que estamos atrapados en ese hiato.(...) Estamos adelantados y atrasados. (Derrida, 1998:131-132)

Isso nos leva ao último apontamento que faço.

Quarto: como se engendra o acontecimento televisivo? Como sabê-lo se estamos atrasados e adiantados em relação ao nosso próprio tempo, se estamos mergulhados num tempo cuja complexidade escapa ao nosso discernimento?

Há mais de um século, Walter Benjamin (1986) já nos alertou para os descompassos que ocorrem quando a massificação de certas técnicas age 
sobre o pensamento que se tinha sobre a sociedade. Lembremos rapidamente as críticas que fez aos que queriam encontrar equivocadamente no cinema os elementos de culto vigentes na arte tradicional... O cinema era o dispositivo dos tempos modernos e Benjamin apontou as profundas mudanças por ele produzidas no modo de percebermos o mundo, tantas e de tal ordem que se deveria repensar as arraigadas noções de arte de então.

Também Derrida afirma que 'mirar televisión es en particular una tarea política, a causa de los efectos que genera en el escenario político, pero también porque debo comprender cómo se hace, cómo se fabrica ${ }^{10}$, quién tiene el poder, quién escoge, cuáles son las relaciones de fuerza, etcétera'. (Derrida, 1998:171)

Mais uma vez proponho que se busque compreender o acontecimento televisivo como uma ethicidade no interior de mundos televisivos, acontecimento esse que a sua vez se desdobra em memórias televisivas do acontecimento televisivo. O paradoxal efeito de horizonte que criam não é novo nem exclusivo, mas das imagens analíticas de tevê é possível extrair interessantes visões dos nossos próprios tempos.

Nas gramáticas televisivas que venho aprendendo, as mais sólidas molduras-ethicidades televisivas são as emissoras e os canais de televisão; os gêneros; os programas e as outras unidades televisivas autônomas (os promos, as vinhetas e os comerciais); os tempos de TV que instauram panoramas televisivos (as paisagens audiovisuais resultantes de moldurações intrínsecas); a programação (as grades e as imagens em fluxo de um mesmo canal, ou de diferentes canais no caso do zapping); e a própria televisão.

As grades virtuais de programação são talvez a mais sólida das molduras, aquela que as emissoras menos flexibilizam, não apenas por conta de uma replicância relacionada aos segmentos a que se destina tal ou qual tipo de programa, mas também pelos compromissos das emissoras com os anunciantes que compraram aqueles tempos de TV.

Ainda que a atualização das grades varie de emissora para emissora, de horário para horário, a cobertura de grandes eventos programados é em geral o único fato que altera essa estrutura estável. Ah, sim: e o acontecimento! Nesses dois casos, a programação em fluxo abre espaço (tempo. na verdade) para receber o recém chegado, para aquele verdadeiramente outro que não se esperava que viesse, como foi, por exemplo, o ataque às torres gêmeas de Nova Iorque.

Mas também quando a programação em fluxo da TV Globo é atravessada por imagens do Big Brother Brasil, em inserções (molduras) que têm a mesma natureza da dos dois casos citados", há uma série de interessantes enunciações sobre esse reality show e as ethicidades a ele relacionadas, que irão compor, em nossa memória, uma associação de imagens-lembranças: se já não o fazemos, um dia talvez lembremos de replicantes e episódicos casos de $\mathrm{BBB}$ como grandes eventos e acontecimentos televisivos... 
Ora, o voyeurismo televisivo é uma ethicidade enunciada principalmente nos reality shows que se presta maravilhosamente bem para analisar o que a TV ienuncia sobre o voyeurismo que pratica principalmente no jornalismo $\mathrm{e}$ nós programas de auditório. Como acontecimento nos mundos televisivos ${ }^{12}$, o BBB irrompe o continuum da programação em fluxo, tensiona a sólida moldura grade e dá origem a uma imagem dialética (que contém o novo e o velho). Essa imagem ilumina a constelação: traz marcas de uma outra grade, que sobrevive em estado latente, e que foi banida da TV brasileira a partir dos anos sessenta e setenta; mantém em grande medida a lógica da grade atual; denuncia que essa lógica não é a única possível; experimenta novas possibilidades éticas e estéticas.

Estou sugerindo, então, ainda que possa parecer irônico, que o $B B B$ é um acontecimento no interior dos mundos televisivos da TV Globo. Não simplesmente porque a TV o enuncia como tal, mas porque as práticas em relação a esse $T V$ reality show rompem com práticas muito sólidas, habituadas desde outros tempos memoriais da TV brasileira, e sinaliza outro horizonte de expectativa no interior dos mundos televisivos. ${ }^{1}$

Já o ataque às torres gêmeas é um acontecimento televisivo, mas não um acontecimento no interior dos mundos televisivos, pois já se espera que todo acontecimento atravesse a programação de TV em fluxo. Tudo leva a crer que os idealizadores do ataque também esperavam que isso ocorresse, e que pensaram cuidadosamente em' como produzir, com o atentado, imagens singularmente espetaculares que a TV adoraria veicular. Surpreendente, e verdadeiramente outro, um verdadeiro acontecimento no interior dos mundos televisivos, teria sido a televisão não lhes ter dado cobertura!

\section{Notas}

${ }^{1}$ Atentar nos panoramas, por exemplo, à visualização da disputa entre diferentes emissoras usuárias de um mesmo canal, ou entre publicidade e promos de programas, ou entre os panoramas dos

reality shows da TV Globo e os do SBT...

${ }^{2}$ Tomei essa expressão de Eisenstein (1990), que falàva na imagicidade do cinema para designar o filme que ele dizia haver dentro do filme, ao qual era possível associar as montagens que o precederam e que o transcendem, em outras artes, por exemplo.

${ }^{3}$ Conforme propus em Apontamentos para uma história da televisão no Rio Grande do Sul.

${ }^{4}$ Uso o conceito de emolduramento para dizer como significamos as coisas nos processos midiáticos. Enunciados no interior de molduras ou quadros de experiência, os sentidos são significados ou agenciados, entre emissor e receptor, a partir de referências pessoais e culturalmente circunscritas. 
5É patrimônio histórico aquilo que tem valor memorial.

${ }^{6}$ Relacionados aos mundos televisivos, existem seres televisivos. Chamo esses seres de ethicidades televisivas, e elas são subjetividades - as pessoas, os fatos, os acontecimentos, as durações e os objetos - que a tevê enuncia como tais, mas que são, na verdade, seres televisivos, virtualidades que se atualizam em certas práticas de uma e outra emissora, em um e outro programa. em um e outro contexto. E aí volto a Bergson: sujeito ou subjetivo é tudo aquilo que muda de natureza ao se dividir, e assin, as subjetividades são tendências, principalmente durações, que são contrariadas por outras tendências. São também virtualidades, cuja realidade é atualizar-se.

${ }^{7}$ O sentido de artefato abre o texto de Derrida: '(...) Hoy más que nunca, pensar nuestro tiempo, sobre todo cuando a su respecto se corre el riesgo o chance de la palabra pública, es tomar nota, para ponerlo en práctica. del hecho de que el tiempo de esa misma palabra se produce artificialmente. Es un artefacto. En su mismo acontecer, el tiempo de ese gesto público es calculado, forzado, 'formateado', 'inicialado' por un dispositivo mediático (hagamos uso de estas palabras para ir de presa)'. A seguir, relaciona a atualidade em geral a dois termos afins: 'artefactualidad' e 'actuvirtualidad'. (Derrida, 1998:15)

${ }^{8}$ Há vários autores que dizem coisas parecidas, e cito Derrida apenas porque estou trabalhando com ele nesse momento em minha pesquisa.

${ }^{9}$ Atentem que estou falando aí de uma ethicidade televisiva. Trata-se de um acontecimento enunciado pela TV como tal, mas que é um acontecimento televisivo.

${ }^{10}$ Grifo meu.

"A cobertura de grandes eventos programados e o acontecimento...

12 Atentem que aqui estou falando de um acontecimento dentro de mundos televisivos. A cotidianidade desses mundos, seu continuum. sua reality, é descontinuada pelo acontecimento $B B B$. Esse imaginário de acontecimento é minimamente partilhado com o de acontecimento e de acontecimento televisivo.

${ }^{13} \mathrm{E}$ isso não tem nada ver com o teor eso ha sido que alguns atribuem ao programa...

\section{Referências}

BENJAMIN, Walter. Magia e técnica, arte e política. São Paulo: Brasiliense. 1986.

BERGSON, Henri. Matéria e memória. 2. ed. São Paulo: Martins Fontes, 1999. 
CANEVACCI, Massimo. A cidade polifônica: ensaio sobre a Antropologia da comunicação urbana. 2. ed. São Paulo: Studio Nobel, 1997.

DERRIDA, Jacques. Ecografias de la televisión. Entrevistas filmadas a Bernard Stiegler. Buenos Aires: Eudeba, 1998.

EISENSTEIN, Sergei. O sentido do filme. Rio de Janeiro: Jorge Zahar, 1990.

_._. A forma do filme. Rio de Janeiro: Jorge Zahar, 1990.

KILPP, Suzana. Apontamentos para uma história da televisão no Rio Grande do Sul: São Leopoldo: Únisinos, 2000.

Ethicidades televisivas. São Leopoldo: Unisinos, 2003.

ROLNIK, Suely. Cartografia sentimental, transformações contemporâneas do desejo. São Paulo: Estação Liberdade, 1989.

WOLTON, Dominique. Elogio do grande público: Uma teoria crítica da televisão. São Paulo: Ática, 1996. 